\title{
Ovarian cyclicity and follicular recruitment in unilaterally ovariectomized mice
}

\author{
R. G. Gosden, Evelyn Telfer, M. J. Faddy* $\div$ and D. J. Brook $† \S$ \\ Department of Physiology, University Medical School, Edinburgh EH8 9AG, UK; \\ ${ }^{*}$ Department of Statistics, University of Birmingham B15 2TT, UK; and \\ $\dagger M R C$ Human Genetics Unit, Edinburgh EH4 $2 X U, U K$
}

\begin{abstract}
Summary. Halving the numbers of follicles in young adult mice by unilateral ovariectomy resulted in compensatory Graafian follicle growth with a reduction by about $25 \%$ of the expected number of oestrous cycles. The impact of the operation on the numbers and dynamics of preantral follicles during the first 2 months after ovariectomy was studied using a compartmental mathematical model to analyse differential follicle counts. There were changes in growth and/or death rates at all stages of follicle development, and the patterns emerging were time-dependent. The rate of follicle survival from the pool of unilaminar stages was paradoxically reduced, but those forming two granulosa cell layers continued to develop towards Graafian size. As the frequency of follicle death declined, the numbers of healthy large preantral and antral stages in unpaired ovaries rose to approach those in pairs of age-matched control ovaries, suggesting that follicles otherwise undergoing atresia were being rescued. In the long-term, follicle dynamics after unilateral ovariectomy at young ages did not appear to compromise fecundity seriously.
\end{abstract}

Keywords: follicles; ovary; unilateral ovariectomy; oestrous cycle; mouse

\section{Introduction}

The ability to restore normal organ function after partial extirpation is widespread in vertebrates but the extent of recovery varies between species, between organs and with age. In young mammalian ovaries, a full quota of ovulations is restored after unilateral ovariectomy in polytocous species. This discovery helped shape early theories about the extrinsic neurohormonal control of ovarian function (Lipschutz, 1928), and unilateral ovariectomy continues to be an important model for studying follicle recruitment.

A considerable body of information indicates that compensatory ovulation involves alleviation of negative feedback influences from the ovary (sex steroids, inhibin) on the pulsatile release of pituitary gonadotrophins, FSH and LH. Particular attention has been paid to a post-operative rise, albeit transient in many studies, of circulating concentrations of FSH (Ojeda \& Ramirez, 1972; Welschen \& Dullaart, 1974; Bast \& Greenwald, 1977; Butcher, 1977; Otani \& Sasamoto, 1982). While a compensatory gonadotrophin response was not detected in a study of unilaterally ovariectomized mice, it was concluded nevertheless that superovulations were due to negative feedback responses rather than to greater utilization of a fixed amount of hormone (Gibson et al., 1979). As a result of superstimulation by the greater availability of gonadotrophins, a larger number of Graafian follicles reach maturity during each cycle.

$\Varangle$ Present address: Department of Mathematics and Statistics, University of Otago, P.O. Box 56, Dunedin, New Zealand.

§Present address: Department of Medicine, Welsh National School of Medicine, Heath Park, Cardiff CF4 4XN, UK. 
Since the superovulation response of a single ovary in laboratory rodents has a latency of only a few days it has been assumed that supernumerary follicles are recruited from the growing stages rather than from the pool of primordial follicles. Furthermore, it is widely held that multilaminar preantral and/or small antral follicles are rescued from atresia by gonadotrophins, to which they are acutely responsive (Chiras \& Greenwald, 1978; Otani \& Sasamoto, 1982; Hirshfield, 1982, 1983; Meijs-Roelofs et al., 1984). Doubt remains for at least some species whether fluctuations in circulating gonadotrophins are a sufficient explanation for the control of ovulation rates. In sheep, a normal ovarian response to unilateral ovariectomy can occur when hormone concentrations are 'clamped' experimentally (Fry et al., 1987) and, in unoperated ewes during seasonal anoestrus, when gonadotrophin secretion is suppressed, a normal number of ovulations is obtained after administration of hCG (Webb, 1988). These results suggest that ovulation rates may be modified by additional factors such as paracrine influences (Hsueh, 1986) or sympathetic nerves (Gerendai et al., 1978; Curry et al., 1984).

Nevertheless, it is obvious that compensatory follicle maturation can only be sustained by rescuing antral follicles while sufficient recruitment continues from the pool of primordial follicles. Rarely has the impact of unilateral ovariectomy on the numbers of preantral follicles been investigated and there have been no studies of the dynamics, yet this information is needed for predicting long-term fecundity. The following study was therefore designed to estimate the rates of follicle growth and death in young unilaterally ovariectomized inbred mice. This has been achieved by applying data from differential follicle counting to an established mathematical model and comparing results with those from comparable intact animals (Faddy et al., 1987). The long-term effects of unilateral ovariectomy on the frequency of oestrous cycles and the timing of ovarian failure were studied in comparable groups of animals.

\section{Materials and Methods}

Animals. Inbred $\mathrm{CBA} / \mathrm{Ca}$ mice were obtained from the laboratory colony which was maintained at $21^{\circ} \mathrm{C}$ with a photoperiod of $14 \mathrm{~h}$ beginning at 07:00 h GMT. A pelleted diet and water were provided ad libitum. Virgin mice were housed in pairs and vaginal smears were obtained 6 days per week by lavage from 38 days of age. At pro-oestrus, when 41-45 days old, 33 mice were unilaterally ovariectomized and 5 were sham-operated on the right or left side.

Follicle numbers and dynamics. Animals were autopsied 4-50 days after surgery when they presented a prooestrous vaginal smear and were $48-95$ days old. The dissected ovaries were fixed in Bouin's fluid, serially sectioned in paraffin wax at $7 \mu \mathrm{m}$ and stained with haematoxylin and eosin. The numbers of follicles were counted using the classification of Mandl \& Zuckerman (1951) in which the numbers of cell layers and morphology of granulosa cells define preantral follicle stages I-V. The largest stage (VI) was sub-classified as type (a) if the antrum was still forming by coalescence of lacunae, or (b) if an antrum was present.

Differential follicle counts were carried out blindly for each animal at a frequency of every 10th section for all stages except the largest two (Stages V and VI) for which every section was searched. The nucleolus was used as a counting marker and the raw counts were adjusted using correction factors to estimate total numbers. Additionally, the morphological appearance of the larger follicles, at stages V and VI, was recorded to provide an indication of follicular health or atresia. When 3 or more pycnotic granulosa cells were present in the equatorial cross-section, the follicle was considered 'atretic'. The numbers and proportions of atretic follicles at these stages were compared in operated and control animals using the Kruskal-Wallis analysis of variance by ranks.

The raw follicle counts were used to fit a compartmental model describing the numbers of follicles in terms of their rates of movement from stage-to-stage; details of construction and properties of such models have been presented elsewhere (Faddy et al., 1976). Non-parametric regression methods were used to smooth the (highly variable) data into curves describing the dependence of the follicle counts (at each stage of development) on age, for comparison with those obtained from the fitted model (see Faddy \& Jones, 1988). Since follicle counts in the sham-operated group were indistinguishable from those obtained from age-matched intact animals in a concurrent study (Faddy et al., 1987), the compartmental model for these animals was compared with the data and model from unilaterally ovariectomized mice.

Ovarian cycle history. The frequency of ovarian cycles in comparable groups of 20 unilaterally ovariectomized and 21 sham-operated mice were estimated from daily vaginal smears using a standard cytological classification (Nelson $e t$ al., 1982). The animals were killed after exhibiting at least 30 consecutive days of anoestrus. At autopsy, the presence of only one ovary in the unilaterally ovariectomized group was verified and the remaining ovary was processed histologically to assess follicular status. Individuals presenting signs of disease were excluded from the results. 


\section{Results}

\section{Follicle numbers and dynamics}

The total numbers of follicles per animal (including atretic stages) in unilaterally ovariectomized animals at different stages of development $(\mathrm{I}-\mathrm{V}+)$ and at different ages are shown in Fig. 1 . The data obtained from unilaterally ovariectomized animals did not fit the model for the intact group, which indicated that growth and/or death rates differed, and therefore a new compartmental model was constructed. The two models are compared in Fig. 1. On the basis of the known ovulation rate of 7-9 per cycle in this strain (Gosden, 1979), the daily rate of egress from the largest stages $(\mathrm{V}+)$ by ovulation and atresia was constrained to 0.08 to provide a realistic number of follicles maturing during each cycle. The new model had two age phases with a step transition at 67 days to follow the distribution of Stage II follicle numbers. The use of different ages for the phase transitions in the two models to improve the fit to the data created difficulties when parameters were compared. Nevertheless, it is clear that many more small follicles were dying than normal in the operated animals. Table 1 shows that in unpaired ovaries the numbers of follicles actually growing to Stage III, when expressed as a percentage of those leaving Stage I, were much lower than those for normal animals at similar ages. Because of some imprecise estimates of death rates at Stages I and II (Fig. 2) and high correlations between estimates ( $r=0.85$ for inflow into Stage II and death rate at same stage in Phase $1 ; r=-0.96$ for the death rates at Stages I and II in Phase 2), the precise apportionment of death between these stages is uncertain, but it certainly appears that death of follicles at these stages was the main cause of low numbers (Fig. 1). The death rates at Stages III and IV (Fig. 2) were negligible, and so virtually all follicles leaving Stage II by growth would reach Stage $\mathrm{V}+$. It was the higher numbers of these follicles maturing in the remaining ovary, although moderating later (Table 1), that were responsible for the post-operative increase of Stage $\mathrm{V}+$ follicles (Fig. I) and the higher rate of outflow by ovulation.

Table 1. Average numbers of follicles entering and leaving successive stages of development (per day) in unilaterally ovariectomized animals as estimated from a compartmental model (Fig. 2)

\begin{tabular}{|c|c|c|c|c|c|c|c|c|c|}
\hline \multirow{2}{*}{$\begin{array}{c}\text { Age } \\
\text { (days) }\end{array}$} & \multicolumn{9}{|c|}{ Stages } \\
\hline & $I \rightarrow$ & $\rightarrow$ II & $\mathrm{II} \rightarrow$ & $\rightarrow$ III & $\mathrm{III} \rightarrow$ & $\rightarrow \mathrm{IV}$ & IV $\rightarrow$ & $\rightarrow \mathrm{V}+$ & $\mathrm{V}+\rightarrow$ \\
\hline \multicolumn{10}{|c|}{ Phase I } \\
\hline 49 & 16 & 16 & 47 & 3.0 & $3 \cdot 0$ & $3 \cdot 0$ & $2 \cdot 7$ & 2.7 & 1.9 \\
\hline 56 & 15 & 15 & 39 & 2.5 & $2 \cdot 9$ & $2 \cdot 9$ & $2 \cdot 9$ & $2 \cdot 9$ & $2 \cdot 3$ \\
\hline 63 & 14 & 14 & 35 & $2 \cdot 2$ & $2 \cdot 8$ & $2 \cdot 8$ & 2.9 & $2 \cdot 9$ & $2 \cdot 5$ \\
\hline \multicolumn{10}{|c|}{ Phase 2} \\
\hline 70 & 26 & 23 & 15 & 0.9 & 1.9 & 1.9 & $2 \cdot 1$ & $2 \cdot 1$ & $2 \cdot 5$ \\
\hline 77 & 22 & 20 & 19 & $1 \cdot 1$ & 1.8 & 1.8 & $2 \cdot 0$ & $2 \cdot 0$ & $2 \cdot 3$ \\
\hline 84 & 19 & 17 & 18 & $1 \cdot 1$ & 1.7 & 1.7 & 1.9 & 1.9 & $2 \cdot 1$ \\
\hline 91 & 16 & 14 & 17 & 1.0 & 1.6 & I. 6 & 1.8 & 1.8 & $2 \cdot 0$ \\
\hline 98 & 14 & 12 & 15 & 0.9 & 1.5 & 1.5 & 1.7 & 1.7 & 1.9 \\
\hline
\end{tabular}

The numbers of follicles appearing healthy at Stage V and Substages VIa and VIb were remarkably similar in the two groups of animals (Fig. 3). The antral types (VIb) numbered 9-10, of which 1-2 were atretic. Most atresia was occurring at stage VIa, this preponderance over other stages being particularly marked in the intact mice although statistically significant only for the older group $(P<0.01)$. The same pattern was obtained when a stricter criterion for atresia was tested, namely, $>20$ pycnotic granulosa cells per section. When the numbers of atretic follicles were expressed as percentages of the numbers at the same stage it was evident that the incidence of atretic 

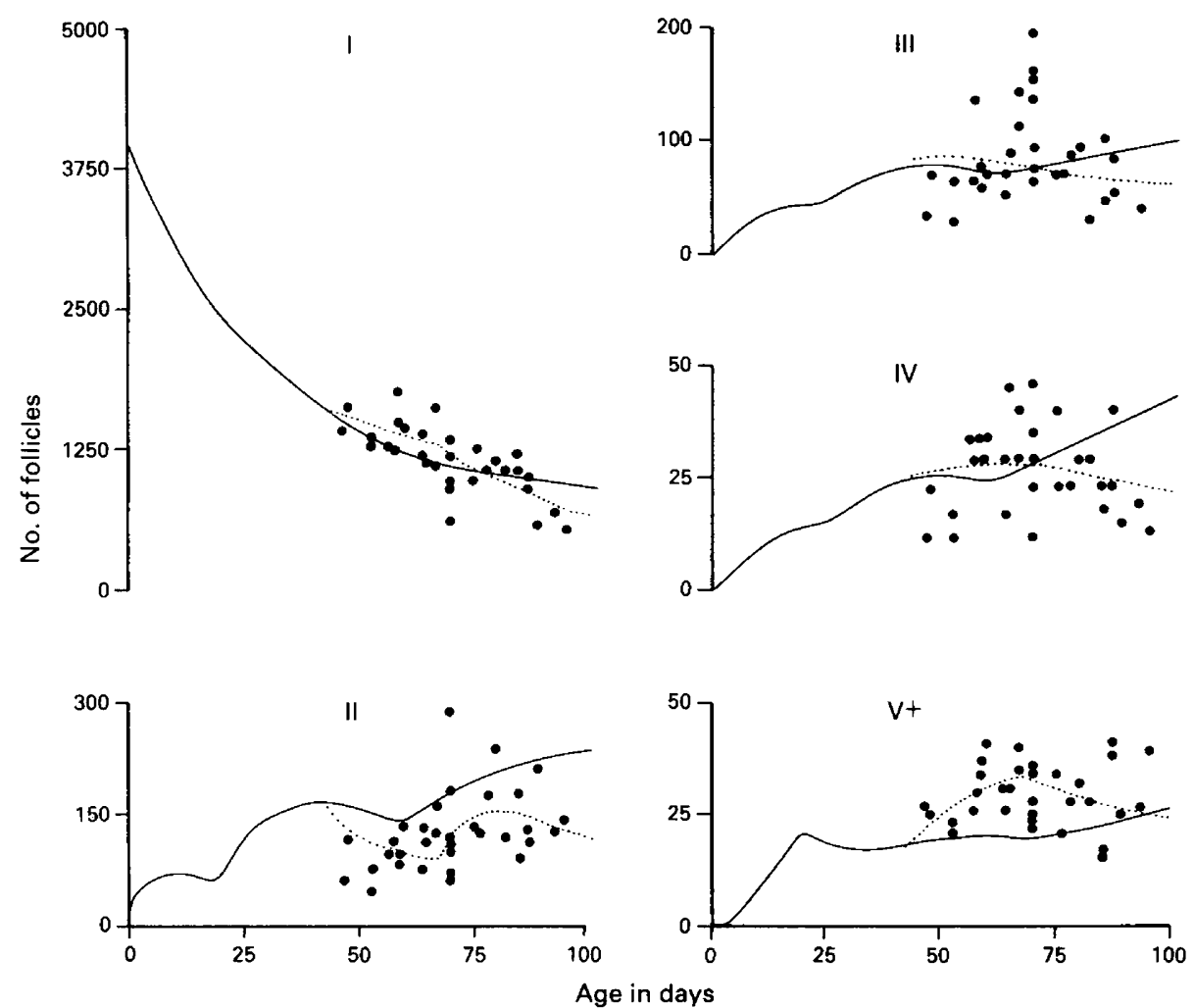

Fig. 1. Graphs showing variation in numbers of follicles at different stages of growth (Stages $\mathrm{I}-\mathrm{V}+$ ) in mice which were unilaterally ovariectomized at 6 weeks of age. The compartmental model (...) has been fitted to the data (see also Fig. 2). Stages V, VIa and VIb were combined into a single group $(\mathrm{V}+)$ because, when considered individually, there were insufficient follicles for reliable estimates to be obtained of growth and death rates. The solid curve $(-)$ describes age changes in one ovary of intact animals.

Stage V and VIa follicles had been halved by unilateral ovariectomy at young adult ages, and this could therefore account for a greater ovulation rate.

\section{Ovarian cycle history}

The results of the longitudinal study of oestrous cycles are presented by 20 -day intervals from 90 days old with the exclusion of 3 animals on the basis of autopsy findings (Fig. 4). More than $90 \%$ of the animals of both groups presented strings of short cycles between 90 and 300 days of age and, on average, approximately half of the cycles were 4 or 5 days long. An incomplete set of records failed to demonstrate any differences between the two groups of animals during the first 40 days after surgery. After 250 days of age, cycle frequency in the unilaterally ovariectomized group diminished, being a result of additional days of either mainly cornified cells (oestrus) or leucocytes (di-oestrus). Prolonged periods of vaginal mucification with leucocytosis (indicative of pseudopregnancy) were rare. The frequency of cycles, whether 4-5 days or longer, declined prematurely in unilaterally ovariectomized animals, of which $50 \%$ had become acyclic at 340 days old, 40 days earlier than the controls. The unilaterally ovariectomized mice had a total of $15 \cdot 34 / 5$-day cycles after 90 days of age as opposed to 20.4 in controls during the same period. Cycle loss was evidently permanent since few, if any, follicles remained after 1 year of age. 


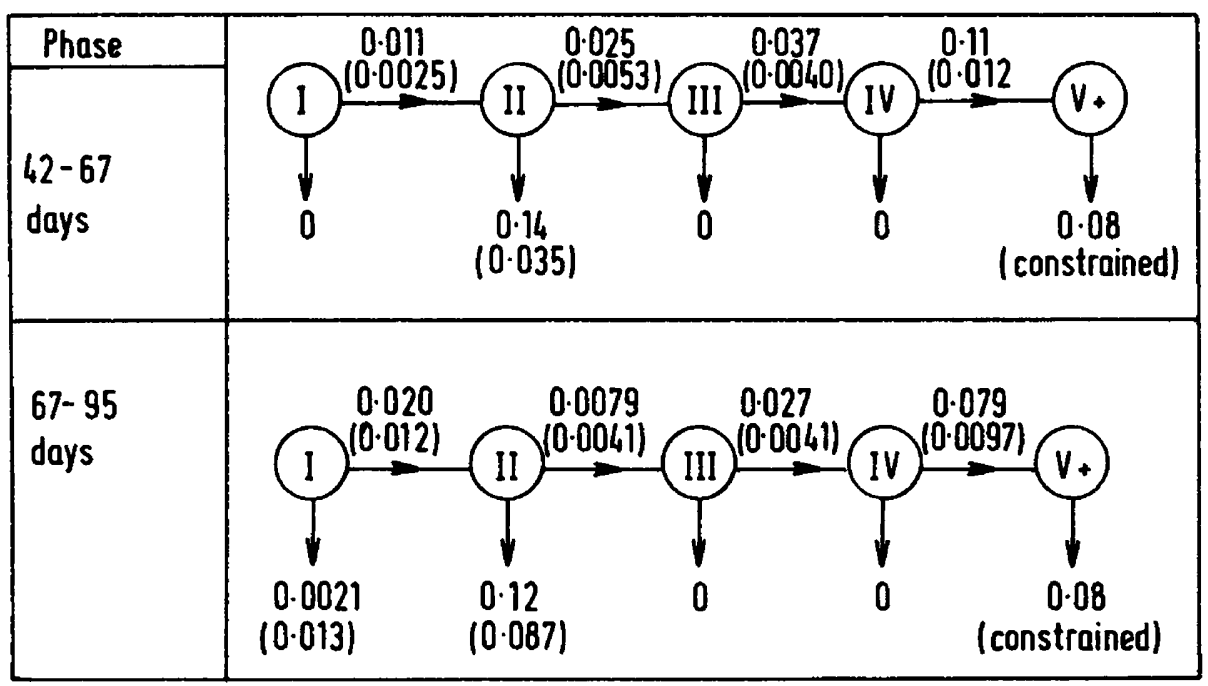

Fig. 2. Estimates of growth (migration) and death rates (with standard errors) of follicles in unilaterally ovariectomized mice (see data in Fig. 1).

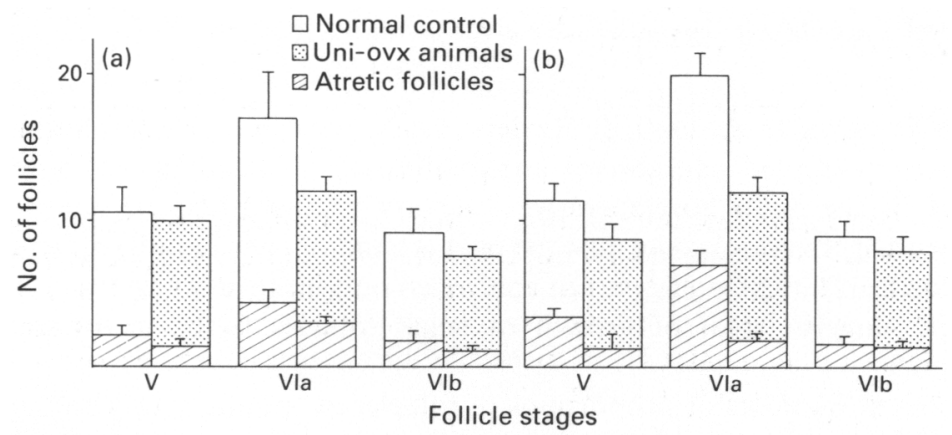

Fig. 3. The numbers of healthy and atretic follicles at three stages of development in intact and unilaterally ovariectomized (uni-ovx) mice aged (a) 42-66 days ( $N=8 \& 14$, respectively) or (b) 67-100 days $(\mathrm{N}=18 \& 19)$. The total height of each bar indicates the total numbers of follicles; values are means \pm s.e.m.

\section{Discussion}

An unpaired ovary can, in theory, maintain compensatory ovulation without extending cycle length by two mechanisms: by rescuing superfluous follicles from the cohort of growing stages and by raising the rate of recruitment from the pool. The ability of young rat ovaries to mount superovulatory responses shortly after treatment with exogenous gonadotrophins or after unilateral ovariectomy is evidence that follicle rescue is taking place (Braw \& Tsafriri, 1980; Hirshfield, 1982). The present findings extend this well-established conclusion to mice, but indicate that unilateral ovariectomy also elicits a response from the preantral follicle population, which appears to be perverse when higher ovulation rates are required. Earlier studies of follicle numbers led to variable conclusions about the effect of unilateral ovariectomy on preantral follicles. In some studies of ageing rats and Mongolian gerbils no changes were found (Hirshfield, 1983; Norris \& Adams, 1982) whereas in others transient or long-term effects were reported (Mandl \& Zuckerman, 1951; 


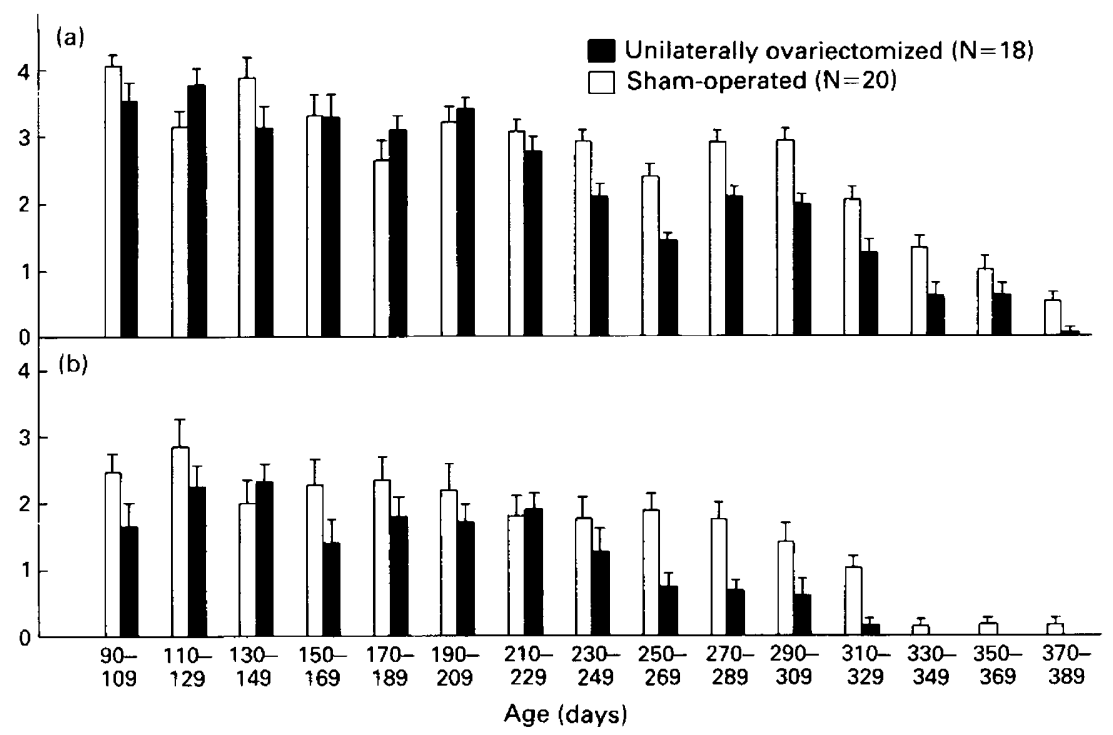

Fig. 4. The frequency of oestrous cycles in mice which were sham-operated or unilaterally ovariectomized at 6 weeks of age. In (a) all cycle lengths have been included but in (b) only 4- or 5-day long cycles are shown. The values are given as means \pm s.e.m.

Dufour et al., 1979; Baker et al., 1980; de Reviers, 1987). A satisfactory resolution of these differences has not been presented and several possibilities exist, including real differences between species or effects of age or of post-operative interval. It should also be remembered that real differences can be easily overlooked against the background of considerable individual variation at a given age, especially if the cycle stage is not controlled or if insufficient time has elapsed for subtle differences in the sluggish rates of growth of small follicles to be manifested as detectable differences in number.

Although different numbers or proportions of follicles at specific stages and ages can indicate alteration of follicle dynamics, the rate of growth and the contribution by follicle death is not usually apparent. The compartmental model has been found to be a useful device for analysing dynamics in normal ovaries and during ovulation suppression (Faddy et al., 1976, 1987; Halpin et al., 1986). It has not been used previously to examine ovaries undergoing superovulation. The range of applications of the model is limited by the precision with which parameters can be estimated, this being unsatisfactory in situations of low follicle abundance as occurs in old ovaries and the largest follicle stages (VI). Consequently, the model was adapted mainly for the preantral follicles in animals less than 100 days old. It shows that much follicle attrition occurred after surgery, but this could not be sustained over most of the reproductive lifespan. No dramatic changes occurred at intermediate follicle stages. While the possibility of ovotoxic effects of anaesthesia cannot be entirely excluded, this effect would be expected to be acute rather than chronic. Had high follicle attrition been maintained, follicle exhaustion would have occurred before the observed onset of acyclicity. When the numbers of Stage I follicles were extrapolated to 300 days of age using parameters for phase 2 , only 7 follicles were predicted in the unilateral ovariectomy group compared with the more realistic figure of 280 in the controls. Doubts about the validity of conclusions drawn by extrapolation are strengthened by studies of another cohort of $\mathrm{CBA} / \mathrm{Ca}$ mice which showed that there was no substantial reduction in primordial follicle numbers or pro-oestrous serum oestradiol concentrations by 5-8 months of age in unilaterally ovariectomized compared with control animals (R. G. Gosden \& C. Mobbs, unpublished). 
A high death rate among small follicles is found at prepubertal ages when it may serve to curb an otherwise explosive increase in follicular mass resulting from large numbers of small follicles being recruited (Faddy et al., 1987). This rate of attrition would not be expected to continue in adulthood, especially when one ovary had been removed; although it is tempting to suggest that the operation reduces the viability of remaining follicles. More chromosomally abnormal oocytes are shed in unilaterally ovariectomized mice (Brook et al., 1984; Eichenlaub-Ritter et al., 1988), but there are fewer grounds for suspecting abnormality at primordial stages than at Graafian ones. Evidently, follicle wastage does not seriously hinder the long-term functioning of the ovary, which has considerable reserve capacity.

The present study cannot identify factors that are potentially responsible for altering follicle population profiles; other methods will be required. There is evidence from other studies that FSH is involved in compensatory maturation of antral follicles in rats (Hirshfield, 1982), and in other species it has been shown to increase DNA synthesis by granulosa cells in cultured preantral follicles (Ryle, 1972; Roy \& Greenwald, 1986). The compartmental model did not indicate effects of unilateral ovariectomy on small growing follicles but there was an increased inflow of mediumsized stages into the largest group $($ Stage $\mathrm{V}+$ ), as would be expected with greater gonadotrophic stimulation. The possibility of a physiological effect on the smallest follicles, albeit lasting for only a few weeks, requires further study and, in view of limited evidence of responsiveness to gonadotrophins, explanation should be sought from among the potential influences of changing numbers of healthy or atretic Graafian follicles and corpora lutea.

The relationship between the fraction of the total follicle population removed and the fraction of potential oestrous cycles lost is not a simple proportion. Halving follicle numbers resulted in the loss of only a quarter of expected cycles. The impact on fecundity caused by extirpating ovarian tissue is predicted to vary with the mass removed and with age. The results obtained by Nelson $\&$ Felicio (1986), who carried out radical ovarian resection, were more dramatic, but still consistent with present findings, as were studies of unilateral ovariectomy carried out by Thung (1961), who was the first author to point out the potential value of this condition as a model of premature ovarian senescence. Early deterioration of ovarian cyclicity is evidently not matched in the CBA/Ca strain by earlier cessation of breeding potential, implying that other causal factors are responsible for infertility (Gosden, 1979). The premature onset of anoestrus in unilaterally ovariectomized animals does support the view, however, that the size of the follicle reserve contributes to the timing of sterility in normal mice (Felicio et al., 1983), at least in this and perhaps other strains in which follicle numbers dwindle rapidly (Jones \& Krohn, 1961).

We thank the Medical Research Council for a grant to R.G.G. and a scholarship to D.J.B.

\section{References}

Baker, T.G., Challoner, S. \& Burgoyne, P.S. (1980) The number of oocytes and the rate of atresia in unilaterally ovariectomized mice up to 8 months after surgery. J. Reprod. Fert. 60, 449-456.

Bast, J.D. \& Greenwald, G.S. (1977) Acute and chronic elevations in serum levels of FSH after unilateral ovariectomy in the cyclic hamster. Endocrinology 100, 955-966.

Braw, R.H. \& Tsafriri, A. (1980) Effect of PMSG on follicular atresia in the immature rat ovary. $J$. Reprod. Fert. 59, 267-272.

Brook, J.D., Gosden, R.G. \& Chandley, A.C. (1984) Maternal ageing and aneuploid embryos-evidence from the mouse that biological and not chronological age is the important influence. Hum. Genet. 66, $41-45$.
Butcher, R.L. (1977) Changes in gonadotropins and steroids associated with unilateral ovariectomy of the rat. Endocrinology 101, 830-840.

Chiras, D.D. \& Greenwald, G.S. (1978) Acute effects of unilateral ovariectomy on follicular development in the cyclic hamster. J. Reprod. Fert. 52, 221-225.

Curry, T.E., Jr, Lawrence, I.E., Jr \& Burden, H.W. (1984) Effect of ovarian sympathectomy on follicular development during compensatory ovarian hypertrophy in the guinea-pig. $J$. Reprod. Fert. 71, 39-44.

de Reviers, M.M. (1987) Hemi-ovariectomy and follicular growth in the immature rat. Acta endocr., Copenh. 114, 547-551.

Dufour, J., Cahill, L.P. \& Mauleon, P. (1979) Short- and long-term effects of hypophysectomy and unilateral 
ovariectomy on ovarian follicular populations in sheep. J. Reprod. Fert. 57, 301-309.

Eichenlaub-Ritter, U., Chandley, A.C. \& Gosden, R.G. (1988) The CBA mouse as a model for age-related aneuploidy in man: studies in oocyte maturation, spindle formation and chromosome alignment during meiosis. Chromosoma 96, 220-226.

Faddy, M.J. \& Jones, M.C. (1988) Fitting timedependent multi-compartment models: a case study. Biometrics 44, 587-593.

Faddy, M.J., Jones, E.C. \& Edwards, R.G. (1976) An analytical model for ovarian follicle dynamics. J. exp. Zool. 197, 173-186.

Faddy, M.J., Telfer, E. \& Gosden, R.G. (1987) The kinetics of pre-antral follicle development in ovaries of CBA/Ca mice during the first 14 weeks of life. Cell Tissue Kinetics 20, 551-560.

Felicio, L.S., Nelson, J.F., Gosden, R.G. \& Finch, C.E. (1983) Restoration of ovulatory cycles by young ovarian grafts in aging mice: potentiation by longterm ovariectomy decreases with age. Proc. natn. Acad. Sci., USA 80, 6076-6080.

Fry, R.C., Clarke, I.J. \& Cahill, L.P. (1987) Changes in gonadotrophin concentrations are not necessarily involved in ovarian compensation after unilateral ovariectomy in sheep. J. Reprod. Fert. 79, 45-48.

Gerendai, I., Marchetti, B., Maugeri, S., Amico Roxas, M. \& Scapagnini, U, (1978) Prevention of compensatory ovarian hypertrophy by local treatment with 6-OHDA. Neuroendocrinology 27, 272-278.

Gibson, W.R., Ingram, B.W. \& Lee, V.W.K. (1979) Can reduced consumption of gonadotrophins account for ovarian compensation in unilaterally ovariectomized immature mice injected with gonadotrophins? $J$. Reprod. Fert. 57, 209-218.

Gosden, R.G. (1979) Effects of age and parity on the breeding potential of mice with one or two ovaries. $J$. Reprod. Fert. 57, 477-487.

Halpin, D.M.G., Charlton, H.M. \& Faddy, M.J. (1986) Effects of gonadotrophin deficiency on follicular development in hypogonadal ( $h p g$ ) mice. J. Reprod. Fert. 78, 119-125.

Hirshfield, A.N. (1982) Follicular recruitment in longterm hemicastrate rats. Biol. Reprod. 27, 48-53.

Hirshfield, A.N. (1983) Compensatory ovarian hypertrophy in the long-term hemicastrate rat: size distribution of growing and atretic follicles. Biol. Reprod. 28, 271-278.

Hsueh, A.J.W. (1986) Paracrine mechanisms involved in granulosa cell differentiation. Clinics Endocr. Metab. 15, 117-134.
Jones, E.C. \& Krohn, P.L. (1961) The relationships between age, numbers of oocytes and fertility in virgin and multiparous mice. J. Endocr. 21, 469-495.

Lipschutz, A. (1928) New developments in ovarian dynamics and the law of follicular constancy. $\mathrm{Br} . J$. exp. Biol. 5, 283-291.

Mandl, A.M. \& Zuckerman, S. (1951) Numbers of normal and atretic oocytes in unilaterally spayed rats. $J$. Endocr. 7, 112-119.

Meijs-Roelofs, H.M.A., Kramer, P., Osman, P. \& Sander, H.J. (1984) Compensatory ovulatory mechanisms operative after first ovulation in rats unilaterally ovariectomized prepubertally. Biol. Reprod. 31, 44-51.

Nelson, J.F. \& Felicio, L.S. (1986) Radical ovarian resection advances the onset of persistent vaginal cornification but only transiently disrupts hypothalamicpituitary regulation of cyclicity in $\mathrm{C} 57 \mathrm{BL} / 6 \mathrm{~J}$ mice. Biol. Reprod. 35, 957-964.

Nelson, J.F., Felicio, L.S., Randall, P.K., Sims, C. \& Finch, C.E. (1982) A longitudinal study of estrous cyclicity in aging C57BL/6J mice. 1. Cycle frequency, length and vaginal cytology. Biol. Reprod. 27, 327-339.

Norris, M.L. \& Adams, C.E. (1982) Effect of unilateral ovariectomy on the population of ovarian follicles relative to age in the Mongolian gerbil (Meriones unguiculatus). J. Reprod. Fert. 66, 335-340.

Ojeda, S.R. \& Ramirez, V.D. (1972) Plasma level of $\mathrm{LH}$ and $\mathrm{FSH}$ in maturing rats: response to hemigonadectomy. Endocrinology 90, 466-472.

Otani, T. \& Sasamoto, S. (1982) Plasma and pituitary hormone changes and follicular development after unilateral ovariectomy in cyclic rats. $J$. Reprod. Fert. 65, 347-353.

Roy, S.K. \& Greenwald, G.S. (1986) Effects of FSH and $\mathrm{LH}$ on incorporation of $\left[{ }^{3} \mathrm{H}\right]$ thymidine into follicular DNA. J. Reprod. Fert. 78, 201-209.

Ryle, M. (1972) The growth in vitro of mouse ovarian follicles of different sizes in response to purified gonadotrophins. J. Reprod. Fert. 30, 395-405.

Thung, P.J. (196I) Ageing changes in the ovary. In Structural Aspects of Ageing, pp. 110-142. Ed. G. H. Bourne. Pitman Medical, London.

Webb, R. (1988) Control of ovulation rate is not seasonal in the ewe. J. Reprod. Fert., Abstr. Ser. 2, 23, abstr.

Welschen, R. \& Dullaart, J. (1974) Serum concentrations of follicle-stimulating hormone and luteinizing hormone after unilateral ovariectomy in the adult rat. $J$. Endocr. 63, 421-422. 